\title{
Balanced renewable energy scenarios: a method for making spatial decisions despite insufficient data, illustrated by $a$ case study of the Vorderland-Feldkirch Region, Vorarlberg, Austria
}

\author{
Pia Nabielek, Hartmut Dumke* and Kurt Weninger
}

\begin{abstract}
Background: An increasing production of renewable energy requires planning strategies that are able to coordinate the higher-level energy goals with local-level land use interests. While the spatial scope of energy objectives is usually set up on a federal state or national scale, decisions to allocate and implement renewable energy sites are often taken on a municipal scale. This leads to a lack of regional coordination, as the task to achieve a balanced regional energy demand and renewable energy production cannot be solved by individual municipalities alone and calls for cooperation on a regional level.

This paper focuses on a recently applied method to support decisions that are committed to empowering the production of renewable energy on a regional scale. In addition, it reflects the generic use of this method, which should be manageable and repeatable under the conditions of an input of only a few quantitative data. At the same time, it addresses the question of how planning decisions, both in spatial and energy planning, may be empowered.

Methods: The research team applied a cardboard games approach that required several steps of analysis. First, energy data and spatial attributes of different renewable energy sources were collected from reference projects and the literature. The end product was a catalogue of renewable energy generators, which also included the estimated energy output ( $\mathrm{kWh} / \mathrm{a}$ ) and land consumption $\left(\mathrm{m}^{2}\right)$ per source. A measuring unit of $\mathrm{m}^{2} / \mathrm{kWh} / \mathrm{a}$ was developed that represented an inverse value for the consumption of heat ( $\left.\mathrm{kWh} / \mathrm{m}^{2} / \mathrm{a}\right)$. Second, the current and future (2030) energy demand of the Austrian region of Vorderland-Feldkirch was estimated for this the pilot study area to which the cardboard games method should be applied, which resulted in two energy demand scenarios for 2030-a "businessas-usual" and an "optimum" scenario. The two scenarios were then related to the current renewable energy goal of the federal state (Vorarlberg) in order to calculate the required share of renewable energy for both the year 2030 and the chosen pilot study area. As a third step, a scenario-building workshop was organized for regional stakeholders and experts in energy planning. About 30 people joined the workshop. There were different backgrounds among the workshop participants: local experts and mayors, researchers from the project itself, and energy and planning experts from Germany, the Netherlands, and Switzerland. The three workshop groups had to develop spatial scenarios for Vorderland-Feldkirch to reach the required share of renewable energy. And as a final step, the resulting strategies derived from the workshop scenarios were evaluated by using a GIS analysis.

(Continued on next page)
\end{abstract}

\footnotetext{
* Correspondence: hartmut.dumke@tuwien.ac.at

Department of Spatial Planning, Vienna University of Technology, Vienna,

Austria
} 
(Continued from previous page)

Results: The cardboard games method produced interesting spatial strategies for achieving an equivalent between energy demand and renewable energy production. The main advantage of the method is that it produces quick results and creates awareness of the land consumption of renewable energy. Furthermore, the cardboard games method worked as a participatory approach to simulating a decision-making process in regional (energy) planning.

Conclusions: The estimated energy scenario (2015-2030) is based on several factors that are unfortunately greatly simplified and/or difficult to verify - where the latter is mainly caused by an almost total lack of useable data. On the other hand, the simplification represents the strength of the method bundle, as it ensures a "generic" quality as well as repeatability of the workflow of standard planning situations for many regions, which is also an important part of the research module profile. Still, an in-depth GIS pre-assessment would further enhance and refine the results.

Keywords: Land consumption of renewable energy production, Participatory approach on a regional (planning) scale, Visioneering of energy scenarios

\section{Background}

The transition from the existing mainly fossil-fuel energy system towards a sustainable one, which is based on renewable energy sources, is on the agenda of policy makers at different levels $[1,2]$. Hence, the increase in energy production from renewable sources is considered as a crucial contribution [3] and even a key factor for achieving this long-term vision [2]. Producing renewable energy often not only requires a huge amount of land, but also has an impact on the environment and puts additional strain on land use [4-6]. Different regional characteristics, e.g., settlement structures, require different energy strategies, which result in optimal solutions which also differ within the regions and implies that a cooperation on a regional scale is indispensable [2]. At the regional planning level, this raises some tricky questions:

- What are the maximum dimensions of energy production sites (regarding both capacity and energy) that would no longer be run by individual municipalities, as the area provides limited potential and a scarcity of planning resources?

- What is an effective setup for energy visioneering on a regional scale, when, as usual, starting with only rudimentary available data?

These challenges are of importance to many regions and researchers. The method presented in this paper focuses on these issues and would be a useful component for enhancing the decision-making processes.

In Austria, ${ }^{1}$ a few practical tools and studies tried not only to merge quantitative data of areas and settlements but also to aggregate energy consumption.

One of these studies [7] lists the average technical (not realizable!) potentials of different renewable energy sources. The results, using the unit $\mathrm{GWh} / \mathrm{km}^{2}$, show a similar value bandwidth as our results compiled in the catalogue. Based on a four-step method of calculating the energy potentials [8], the average technical potential per square kilometer is estimated, whereas the constraints are defined and applied to help ensure a sustainable land use, the reduced potentials for actual land cover are calculated, and finally, the potentials, production, and demands are compared [7]. These steps have been applied in a similar way as in the ERP_hoch3 project.

Berchtold-Domig et al. calculated the primary energy amounts of different renewable energy sources, in each case for exactly $1 \mathrm{ha}$, thus offering a calculation toolbox [4]. It would be an option to apply the results as a kind of benchmark to the results of the ERP_hoch3 project, but this was not yet possible.

In order to support stakeholders in their decisions upon the transition of the energy systems, several tools have been developed. Stöglehner et al. give a comprehensive overview in their study "Tools für die Energieraumplanung" [9]. Possible support ranges from the analysis of the current situation of the energy system and the calculation of the current demand to the generation of different scenarios at different spatial levels. Only a few of them address the regional level and do not support the identification of possible sites for renewable energy sources [9].

To ensure a stable and resilient regional energy scenario, it is also of high relevance to identify how "sustainable regional energy systems" are defined in the first place. Gwehenberger and Narodoslawsky invented a complex and holistic approach, the so-called Sustainable Process Index (SPI). This index calculates, within certain spatial borders (e.g., an "energy region"), the relation between the "required" potential renewable process area and the entire energy potential area within this border. The smaller this (numeric) value is, the more sustainable the renewable energy process within this system would be [10]. Using this method-that was developed in the ERP_hoch3 project-we have been able to demonstrate (at least partly) that this relation could also be used "live" and on a smaller scale than the whole region. 
Regions are not just areas, but also "decision-making spaces". Hence, any decision support tool should not only produce excellent technical results, but should also communicate the benefits of energy scenarios in a way understandable for a non-expert audience as well. Späth and Rohracher addressed this issue in their work on energy regions. In their conclusion, they described that stakeholder's constellations can be quite different from region to region, but obviously combine attractive scenario storylines with a spatial discourse over different geographical levels which was very helpful during the case study comparisons they provided. The "guiding visions" as a tool to mobilize stakeholders is considered of high importance [11]. Furthermore, decision support systems and tools-rather often with the support of GIS systems-have been defined and designed to mobilize stakeholders in their decision processes. Wissen and Grêt-Regamey also presented a participatory concept for determining regional potentials for renewable energy incorporating GIS support and a workshop with relevant stakeholders [12].

The presented method is similar to that by Wissen and Grêt-Regamey and addresses the issues mentioned in the last paragraph. While GIS is used in a rather basic way, in particular the "games" part of the method is considered a new approach supporting the raising of awareness of the involved stakeholders. This also helps in revealing their preferences that are required in a more complex multi-criteria decision analysis [13, 14], which the method itself is not aiming at being merely a support tool in such a process.

Concerning regional energy scenarios, Blaschke et al. mentioned that spatial planning in most European countries-except at the small-scale communal level-does not deal explicitly with "energy spaces", e.g., with reserving areas for future energy corridors or for the spaceconsuming generation of renewable energies. Those "energy landscapes" require modelling in time and space, both for the energy demand side and production potentials [15]. The research of Blaschke has been especially focused on biomass but has generally pointed out that energy scenarios need to combine GIS, spatial disaggregation techniques, and geovisualization. This work pattern has a clear similarity to that one presented in our paper.

In terms of settlement patterns and their function in a regional energy scenario, some studies by Gernot Stöglehner have inspired our work. He was one of the first researchers who described so-called Integrated Spatial and Energy Planning [16]. In particular, the typology of two rural and two urban settlement patterns (with different roles in the production and consumption task in an energy region) encouraged the project team of ERP_hoch3 to develop the energy scenario games board. Also, the toolbox RegiOpt [17] is related to the method presented in this paper. Although the toolbox does not exactly visualize where the energy production sites should be "pinned", it supports calculating the long-term analysis effects and benchmarks for energy production and consumption amounts on a regional scale.

Creating a regional energy scenario is a very tricky task. It is not relevant whether the fundamental data situation is satisfying or not; typically, one has to create a scenario that includes both a few powerful production sites and a lot of decentralised, small-scale units that are used-one could call it a "swarm". The latter effect, the so-called energy sprawl, is discussed and considered very controversial. Moroni et al. [18] argued that renewable energy scenarios do not automatically have a negative spatial effect but facilitate the creation of decent polycentric energy systems which also care for the demand side (i.e., the building-related renewable energy production [19]). This paper contributes to this process-especially for typical circumstances of work in practise, where data availability is rather often an issue that cannot be solved (at least not in a timely fashion and usually requiring much additional effort).

For that reason, data estimations (using simple GIS modelling and/or questionnaires), instead of decent and accurate actual consumption data, are usually used in the "Klima- und Energiemodellregionen" (KEM) ${ }^{2}$ and other "energy regions". The research team at first tried to start in a similar way in the case study area, but soon, the results turned out to be very unsatisfying. This "information gap" in the regional fundamental research was a motivation to try to develop a new approach-by designing a database which includes the existing renewable energy sites and their land use consumption as well as any competition aspects. This setup has functioned as a starting point to go on with an energy scenario workshop, which then was post-evaluated using a GIS modelling of the core potential areas for renewable energy production that were designated during the workshop.

\section{Methods}

The technical literature presented only a few resources and studies that compare the land use aspects of many renewable energy carriers. For this reason, one of the modules in the research project ERP_hoch3 [20] gathered data in a catalogue of existing renewable energy sites. The main unit of measurement was square meter per kilowatt hour and year $\left(\mathrm{m}^{2} / \mathrm{kWh} / \mathrm{a}\right)$. This unit represented a counterpart of the much more familiar unit kilowatt hour per square meter and year $\left(\mathrm{kWh} / \mathrm{m}^{2} / \mathrm{a}\right)$, which-for instance-is frequently used to display the thermal energy consumption of buildings.

The workflow to fill out the catalogue consisted of the following steps: As regards wind power, solar energy, 
and waterpower, the existing Austrian sites were checked for their capacity (W) and their energy output (Wh per year). The latter can vary widely in the site parameters, on the one hand, mainly in the maximum power and annual overall workload depending on hours of sunshine or wind within a year. The biomass and geothermal energy productivity, on the other hand, have different spatial efficiency factors-mainly the harvesting quota and intensity, or the depth and total amount of the wells. For all energy site records, the entire horizontal land coverages per facility $\left(\mathrm{m}^{2}\right)$ were measured (using satellite maps) and then divided by the energy output $(\mathrm{kWh} / \mathrm{a})$. After collecting some of these samples from all over Austria, verifications and corrections were carried out in order to perfectly match the local preconditions in the test region "Regio Vorderland-Feldkirch". Table 1 shows some of these examples, listed ascending by the spatial efficiency factor $\mathrm{kWh} / \mathrm{m}^{2} / \mathrm{a}$.

The case study region "Vorderland-Feldkirch" mainly consists of a number of towns linearly located alongside the Rhine between Austria and Switzerland with about 60,000 inhabitants has established an institutionalized regional management of the members (13 municipalities).

One goal of the project has been to examine which kinds of renewable energy are suitable to satisfy the demand within the region of interest. To achieve this, knowledge about local conditions that either enhance or impede the utilization of renewable energy sources, as well as knowledge of the energy demand in the study region, is required.

Analysis of the data showed that the required information is not available in most parts of the region-not even for the existing facilities. By inquiring local stakeholders, some basic data could be gained, but the following evaluation indicated that these were not sufficient by far. In an alternative approach, a basic GIS analysis was carried out to determine areas within the region suitable for the generation of renewable energy-e.g., wind power based on studies that have already been conducted in Vorarlberg, or on the evaluation of topography, solar radiation, and settlement structures for the analysis of solar energy. The results were then summarized in a map booklet to be used later.

As a second step, future energy demand was calculated. Based on existing data on energy consumption of private households, on prognosis of population growth, and on buildings as well as on statistical distribution of energy demand within different sectors, all published by Statistik Austria and Land Vorarlberg [21, 22], a simple model was created to assess the energy demand of the region of Vorderland-Feldkirch for the year 2030 (Fig. 1).

Two scenarios were calculated: one, called BAU (business as usual), under the assumption there will be no behavioural changes and a second one, called OS
Table 1 Samples from the renewable energy site database for heat and electricity production

\begin{tabular}{|c|c|c|c|}
\hline & Renewable energy carrier & $\begin{array}{l}\mathrm{m}^{2} / \\
\mathrm{kWh} / \mathrm{a}\end{array}$ & $\begin{array}{l}\mathrm{kWh} / \\
\mathrm{m}^{2} / \mathrm{a}\end{array}$ \\
\hline Heat & $\begin{array}{l}\text { Biomass from forests, combustion of wood } \\
\text { chips } \\
\text { Austrian average of heat output, incl. a heat } \\
\text { net connection }\end{array}$ & 0.568 & 1.76 \\
\hline Heat & $\begin{array}{l}\text { Biomass from maize } \\
\quad \text { Austrian average of heat production with } 1 \\
\text { or } 2 \text { harvests per year, biogas combustion, incl. } \\
\text { a heat net connection }\end{array}$ & 0.169 & 5.9 \\
\hline Heat & $\begin{array}{l}\text { Biomass, fast-growing shrub, poplars } \\
\quad \text { Austrian average of heat production with } 1 \\
\text { or } 2 \text { harvests per year, wood chip combustion, } \\
\text { incl. a heat net connection }\end{array}$ & 0.142 & 7.04 \\
\hline Elec. & $\begin{array}{l}\text { Wind turbine, middle-sized } \\
\quad \text { (Single or row setup) Capacity: } 0.5 \mathrm{MW} \text { per } \\
\text { turbine Location: Waldviertel, Lower Austria }\end{array}$ & 0.098 & 10.19 \\
\hline Elec. & $\begin{array}{l}\text { Wind park, large } \\
\text { (Cluster setup) } \\
\text { Capacity: } 3 \mathrm{MW} \text { per turbine } \\
\text { Location: Neusiedl, Burgenland }\end{array}$ & 0.081 & 12.2 \\
\hline Elec. & $\begin{array}{l}\text { Wind turbine, large } \\
\quad \text { (Single or row setup) } \\
\quad \text { Capacity: } 3 \text { MW per turbine Location: } \\
\text { Neusiedl, Burgenland }\end{array}$ & 0.04 & 25 \\
\hline Heat & $\begin{array}{l}\text { Low-temperature geothermal source } \\
\text { (Closed heat exchange devices) } \\
\text { Well-field, depth } 100 \mathrm{~m} \\
\text { Energy output: Austrian average }\end{array}$ & 0.032 & 30.4 \\
\hline Elec. & $\begin{array}{l}\text { Large photovoltaic power plant } \\
\text { Collector modules on open land or on large } \\
\text { flat roofs } \\
\text { Location: Oberzeiring, Steiermark }\end{array}$ & 0.019 & 52 \\
\hline Heat & $\begin{array}{l}\text { Large solar-thermal power plant } \\
\text { Collector modules on open land or on large } \\
\text { flat roofs } \\
\text { Location: Vienna }\end{array}$ & 0.008 & 125 \\
\hline Elec. & $\begin{array}{l}\text { Small photovoltaic power plant } \\
\text { Coverage of a complete roof } \\
\text { Location: Vienna }\end{array}$ & 0.007 & 145 \\
\hline Heat & $\begin{array}{l}\text { Small solar-thermal power plant } \\
\text { Coverage of a complete roof } \\
\text { Location: Vienna. }\end{array}$ & 0.003 & 297 \\
\hline Elec. & $\begin{array}{l}\text { Middle-sized river power plant } \\
\text { Capacity } 1.8 \mathrm{MW} \\
\text { Location: Ingering, close to Spielberg, } \\
\text { Steiermark }\end{array}$ & 0.0005 & 2200 \\
\hline
\end{tabular}

(optimistic scenario), assuming at least small energy savings can be achieved due to a raised energy consciousness. In these scenarios, storage and transmission losses have not been considered as they were beyond the scope of the study.

The authorities' plan in Vorarlberg is to use only energy from renewable sources by the year 2050 [23]. To achieve this, the production of renewable energy has to be increased significantly by 2030 (assuming a linear approach). The actual required amount is based on the 


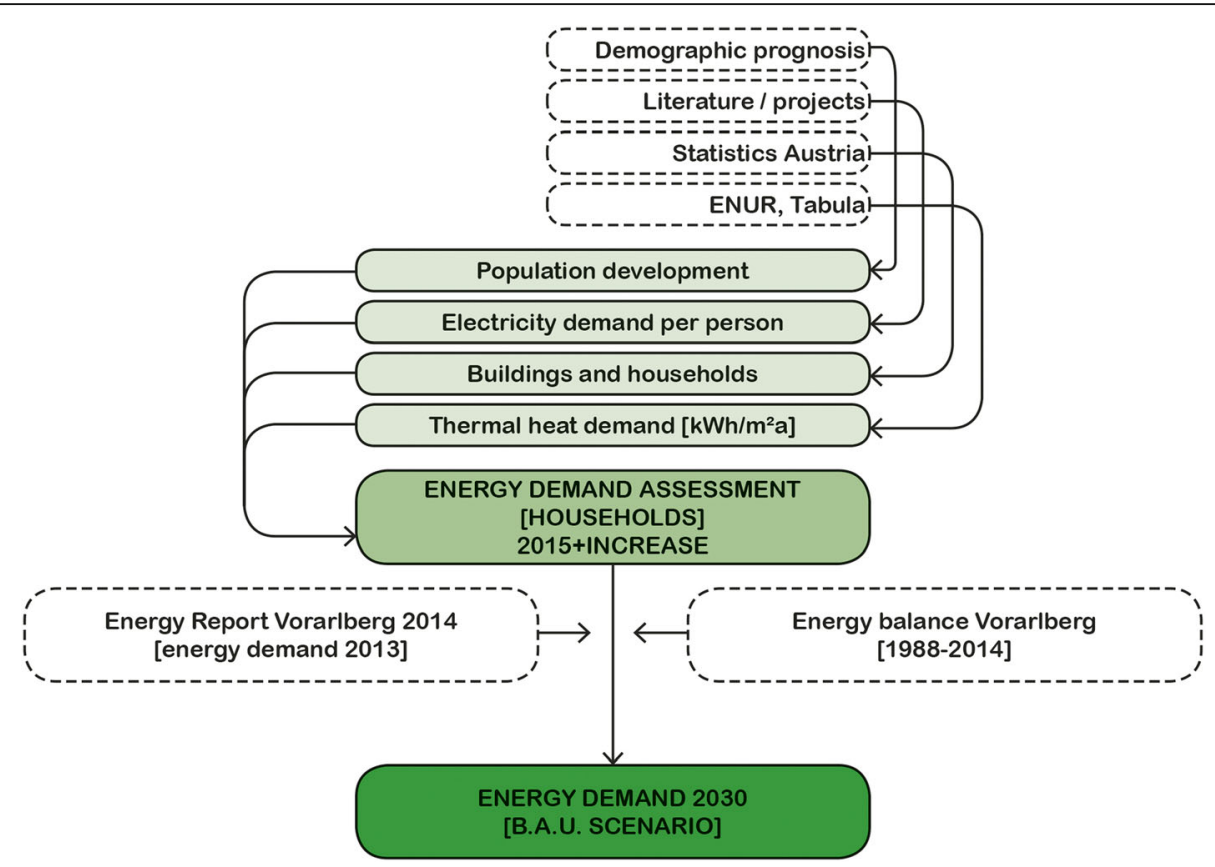

Fig. 1 Data sources and workflow for the assessment of the regional energy demand in 2030 (BAU scenario)

results of the estimation. Taking into account that a proportion of today's energy production is already based on renewable energy sources, only the gap between today's production and required future amount has to be covered by additional renewable energy sources being installed by 2030 .

It is also worth mentioning that the accuracy of the estimation is not of that high importance-even if there are some deviations, the strategies to implement the increase of renewable energy production will still be correct, if prioritized correctly (e.g., focusing on solar energy before targeting wind power). Deviations might occur in a later phase, when-almost certainly-more data will be available to be used to revise the strategy.

The applied "planning game" method for the creation of energy scenarios for Vorderland-Feldkirch is based on methods of research by design [24-26] and participatory approaches to engage stakeholders in a research process. As energy scenarios deal with uncertain futures, decision-making is often based upon non-quantifiable factors. It is therefore important to enable exchange and synthesis of ideas between decision-makers and scientists in scenario analysis. Research by design, in turn, is used to support the process of establishing a dialogue between these key actors. In line with Sijmons et al. [27], this method is used for the inventory of the spatial footprints of different types of energy carriers and energy chains. Furthermore, the aim was to create a variety of possible scenarios instead of one "optimum" solution. From this, key strategies developed in the different scenarios could be synthesized and analysed, according to the similarities and differences in the combinations of energy sources and land use. In a last step, by overlay of matching spatial strategies, the renewable energy potentials for Vorderland-Feldkirch were re-evaluated using GIS analysis.

The main task was therefore to set up a workshop format that allowed comparable scenarios in a parallel working process of approximately 30 participants with different professional background to be created. The chosen format was able to simulate a "planning game" by organizing a scenario creation in three groups that would work, or "play", using the same task and the same material. Each group consisted of experts in energy planning as well as stakeholders of the region. Therefore, the planning game had to be easily understood by the participants with limited knowledge in energy technology but, concurrently, it had to contain all the necessary information to come up with scientifically documented and comparable energy scenarios. In this respect, one main challenge was to find an analogue way to record the estimated energy output of spatial decisions. Different renewable energy sources had to be represented in such a way that the participants are able to judge their spatial impact and, at the same time, to record their contribution to a potential energy scenario. To round off the service, the chosen mix of energy carriers used in the energy scenarios were documented using a suitable "map legend".

The final workshop material consisted of a large cardboard and several boxes of pins of different colour and 
size. In addition, a booklet containing thematic maps of the region provided the background information with regard to the existing energy facilities, energy consumption, and renewable energy potentials. The information provided on the cardboard (Fig. 2) was composed of a map of Vorderland-Feldkirch, a so-called scenario calculator in the form of a table of dots (on the bottom) and a legend of different renewable energy carriers (on the right). The main purpose of the map was to allow the participants to easily navigate and detect potential sites for the application of renewable energy. The map therefore included rather general information regarding the topography, administrative borders, and a basic differentiation of land use. Some functions relevant for renewable energy were highlighted: the protected areas, the existing buildings (especially large roof areas), the main transport axes, and the forest areas as well as the commercial and industrial areas and water bodies.

Based on the " $\mathrm{m}^{2} / \mathrm{kWh} / \mathrm{a}$ " catalogue, a selection of renewable energy sources that could be potentially applied in the region of Vorderland-Feldkirch was chosen. To be able to locate this selection in the regional map, the designated sources were marked with pins of different colours and sizes. This resulted in a pin-set of 11 sources (Fig. 2), where each source produced an estimated amount of heat and electricity (GWh/a). To avoid complex numbers, the energy output of each source was represented by dots. Furthermore, the size of the pin material was on scale, which meant that the workshop participants could immediately capture the area demands of the pinned sources on the regional map. Thus, the pins were used to "locate" the possible renewable energy sources within the region as long as the two energy scenarios BAU and OS were covered (Fig. 3). The booklet of thematic maps served to facilitate the process of identifying the areas which proved to be suitable for the production of renewable energy, while providing background information of the existing facilities, the energy demand, and the energy potentials. The scenario calculator recorded the "sited" share of renewable energy in relation to the total amount of energy required by the scenarios BAU and OS.

Within the workshops, the participants identified several areas (patches) within the region that have the potential to be used for the production of renewable energy-namely, wind power, biomass, solar energy (photovoltaic as well as solar-thermal power), geothermal power, and water power (see Fig. 4). Overall, 19 patches have been identified, giving a realizable amount of energy being created based on the values in Table 1.

In order to get a more realistic estimation, one has to take a closer look on these patches in order to eliminate those ones that in fact are not qualified for energy production due to reasons like being located in a preservation area, being close to settlement areas, having improper zoning restrictions, and other reasons. This can rather easily be done with the support of local stakeholders based on local knowledge (e.g., local authorities, local planners and others) but usually needs some time. Therefore, the research team tested an additional approach. Based on the patches identified in the workshops, a GIS analysis was carried out to automatically identify and disregard unsuitable areas within the patches in order to obtain a more realistic estimation of the possible amount of renewable energy that might be created within these patches. The analysis was done based on the data from both the CORINE Land Cover project of the European Environment Agency and the

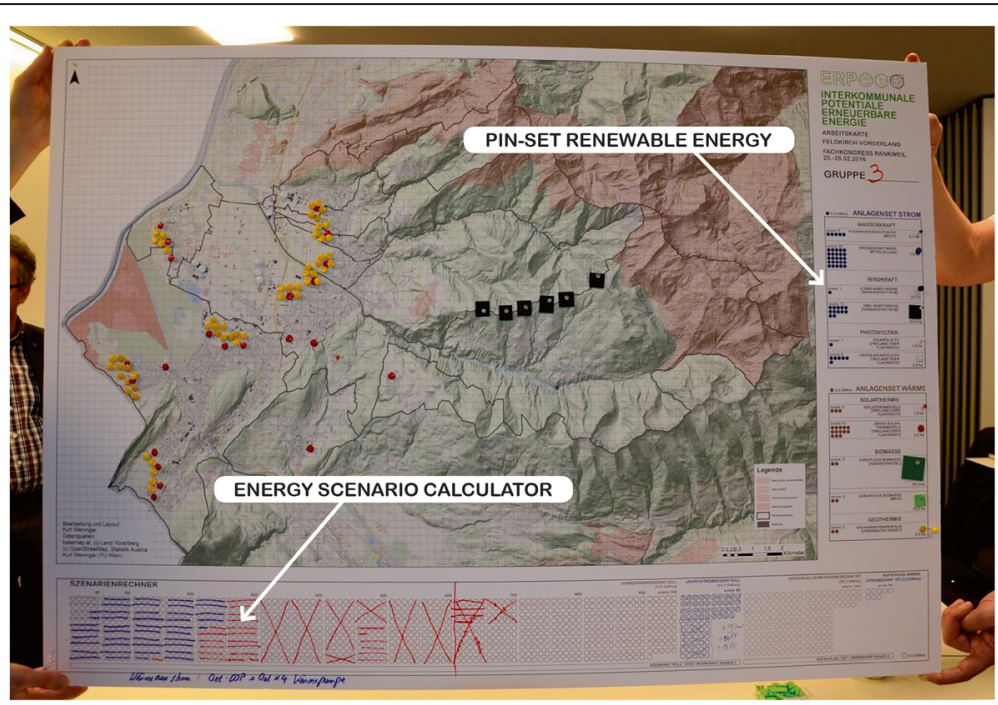

Fig. 2 Cardboard for creating energy scenarios in the region of Vorderland-Feldkirch 


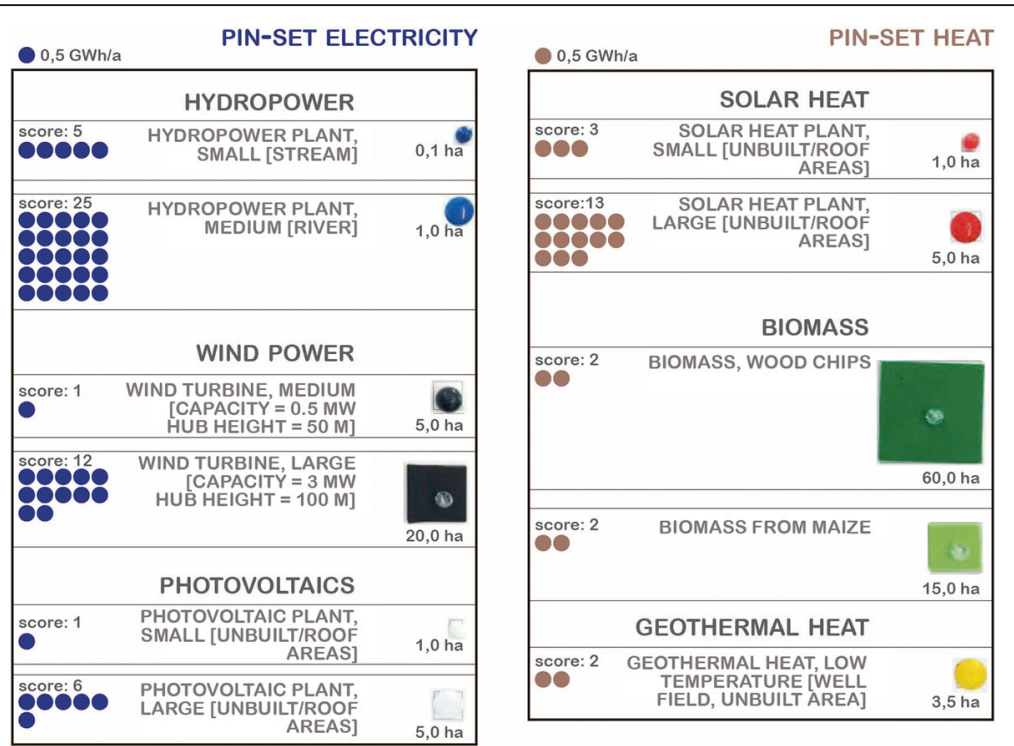

Fig. 3 Pin-set for allocating different renewable energy sources on the cardboard

zoning data of Vorarlberg in combination with the building data from the OpenStreetMap project. In Figs. 5 and 6, the results of both approaches for patch no. 2 are presented.

It is clearly evident that there are differences in the classification as well as the level of detail. This is due to the fact that CORINE is not able to classify any areas smaller than 25 ha. Moreover, it is obvious from the example of patch no. 2 that it would not be possible to use the entire patch area for the generation of renewable energy. All classes of areas for both-CORINE and zoning-have therefore been assigned a "suitability grading" for different sources of renewable energy in order to do the automated recalculation.

\section{Results}

Concerning the area efficiency of the renewable energy site records, it was a surprising to see the enormous

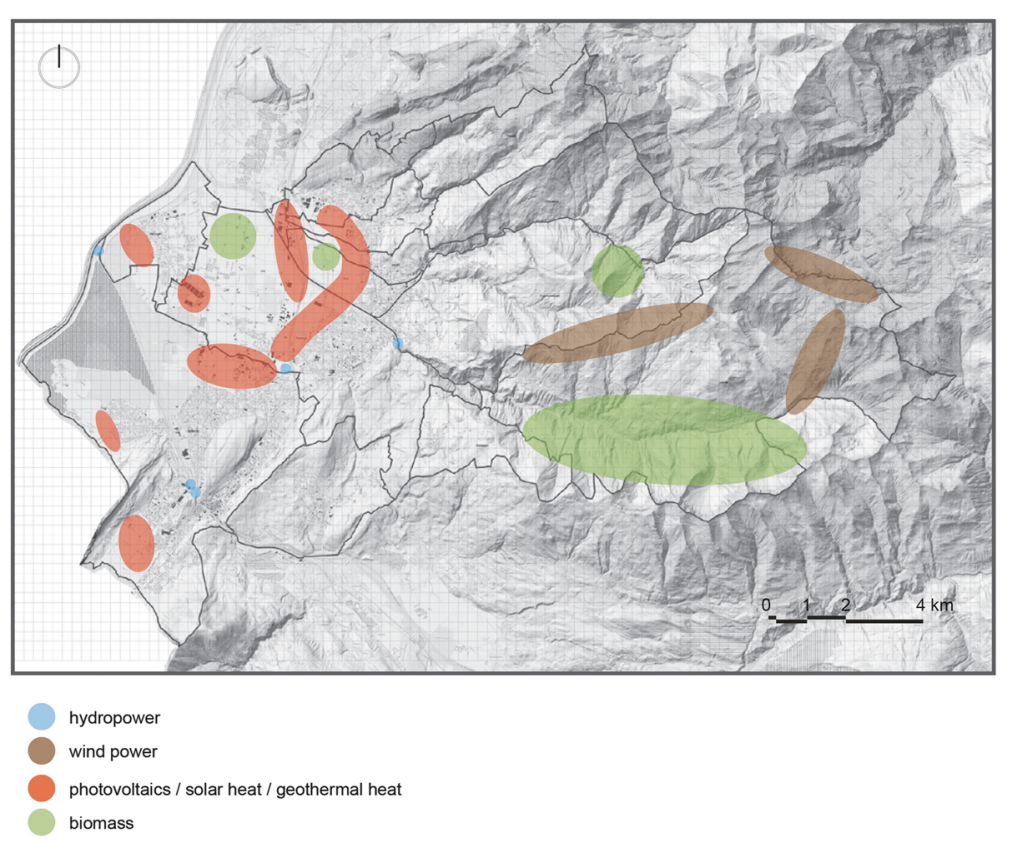

Fig. 4 Aggregated result of three scenarios developed during the workshop: the identified areas for the production of renewable energy in the region of Vorderland-Feldkirch 
bandwidth range of the $\mathrm{m}^{2} / \mathrm{kWh} / \mathrm{a}$ values. Biomass heat from forest (wood chips) requires 1300 times more land than a river power plant (per $\mathrm{kWh}$ and year). The tree map in Fig. 7 displays the relation between the required amounts of land for some examples; also, it shows some classifications of the land use competition and environmental impact in $3^{\circ}$.

During the next step (the workshop), the participants were able to meet the goals of the lower energy demand of scenario "OS". Furthermore, two out of three groups also succeeded in covering the higher energy demand of scenario "BAU". The outcome of the groups can be divided into three main topics: the chosen mix of renewable energy sources, the spatial-qualitative principles concerning the distribution of plants, and the preferences for potential land-use combinations.

For the first topic, the aggregated results show that the participants judge the potential to expand the traditional forms of renewable energy (hydropower and biomass) rather low. Most sites are already in use, and therefore, these sources do not have enough potential to cover the energy scenarios. This is only possible in combination with sources that have not yet frequently been used. Sources that were considered to have high potential were wind power and photovoltaics for the production of electricity and the large-scale exploitation of solar and geothermal heat.

The second topic refers to the spatial-qualitative principles to site renewable energy. Approaches of participants to allocate sites for the creation of renewable energy varied from technical/down-to-earth approaches, which are characterized by the preference for sites being considered to be most efficient, for approaches that are strongly context-related/selective. The latter approach does not prioritize energy efficiency but disregards both the spatial compatibility and/or any considerations with regard to landscape preservation. The common assumption that the hinterland is the main source of renewable energy could not be confirmed. Instead, the participants had identified the largest renewable energy potential in the direct vicinity of the existing built-up areas rather than in remote countryside areas. The results showed interesting spatial strategies such as clustering renewable energy plants alongside mobility axes and settlements. The plants were pinned according to the principle of "filling potential gaps"-using sites that were, according to the knowledge of the participants, still unused. The same principle was used to identify the biomass potentials. Only a few forest and agricultural areas were selected.

Concerning the third topic, depending on the energy source, similarities and differences were detected in what participants considered suitable land-use combinations. All groups preferred to site wind turbines in a concentrated way on ridges (where the highest energy gain is to be expected) and placed photovoltaic systems not only onto large-scale roof areas, but also within commercial areas and brownfields. The outskirts of towns and villages and open areas adjacent to roads and industry were the preferred areas for the large-scale exploitation of solar and geothermal heat.

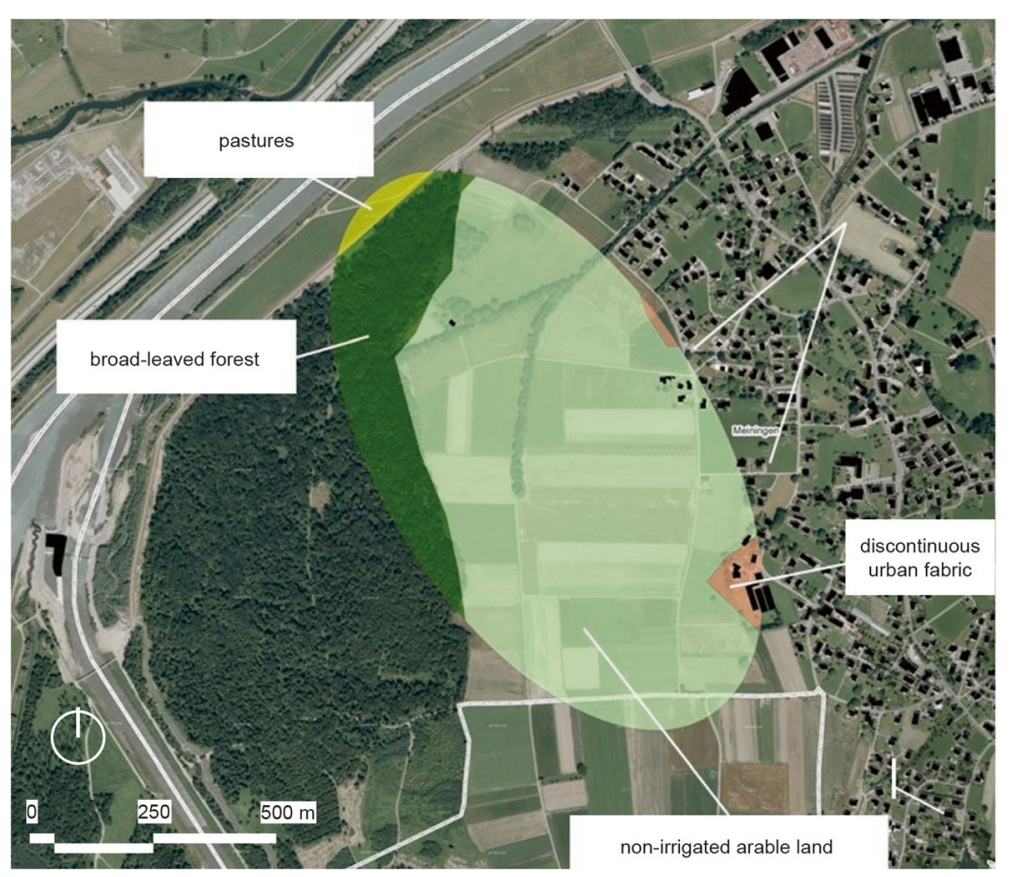

Fig. 5 Areas within patch no. 2: land classification using CORINE Land Cover 


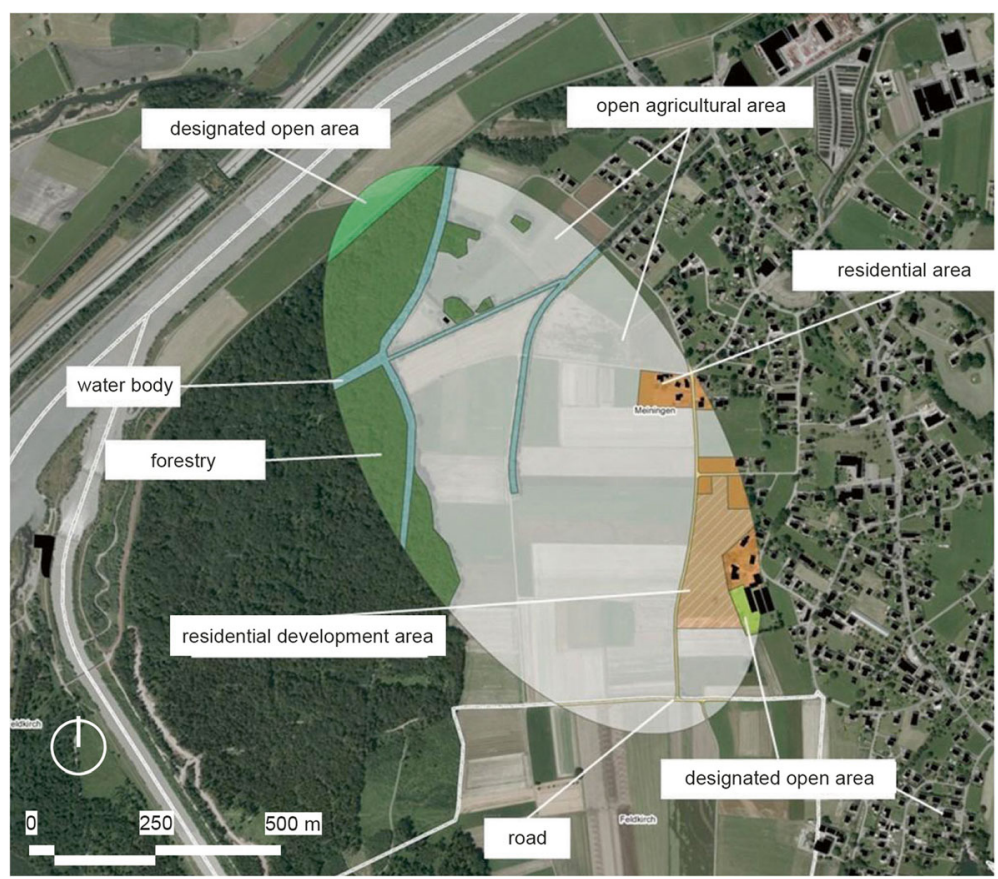

Fig. 6 Areas within patch no. 2: zoning classification using the municipality of Meiningen

Tables 2 and 3 show the results of the GIS analysis of patch no. 2 (see Figs. 5 and 6) combined with the suitability grading of different types of areas for the use of photovoltaic power generation.

First of all, it is evident that in both cases, not all of the areas can be used for the generation of photovoltaic energy; the theoretical amount of $\sim 673.000 \mathrm{~m}^{2}$ has to be reduced by at least $20 \%$. Also, one can see that when using the more detailed zoning data, an additional amount of $\sim 10 \%$ of the area has to be classified as unsuitable in the depicted case.
By using the reference values in Table 1, it is also possible to calculate an estimate of the amount of energy that can potentially be generated within the patches from different renewable energy sources-e.g., geothermal and solar power in patch 2 (Table 4).

\section{Conclusions}

\section{Summary}

The method shown in this paper consists of three modules: a catalogue of renewable energy production reference values, a regional energy BAU/OS scenario, and a

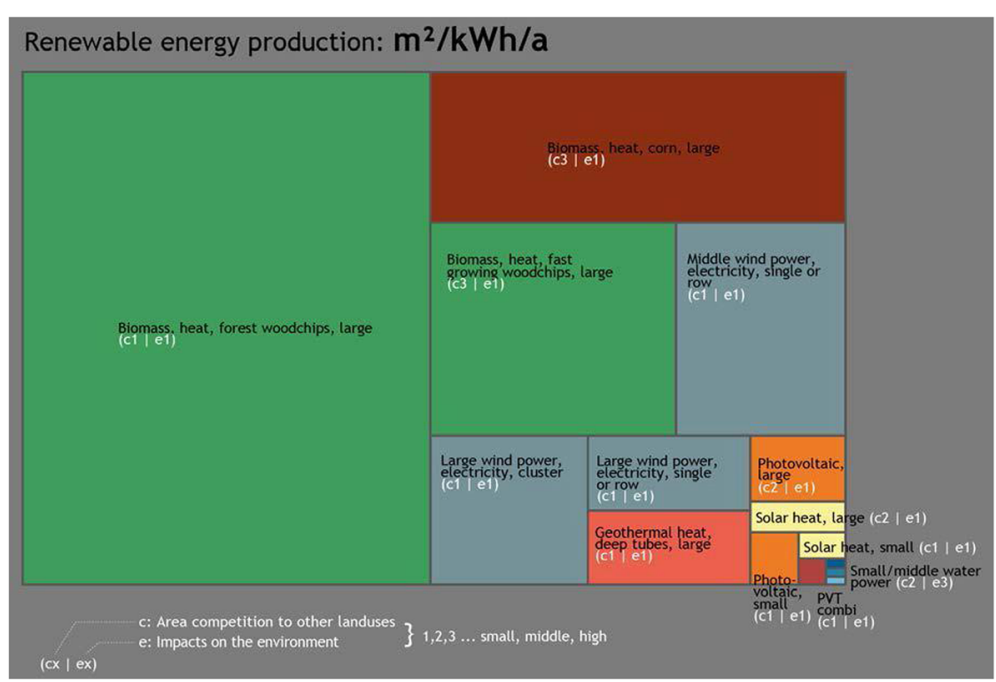

Fig. 7 Comparison of the spatial demands of different types of renewable energy production $\left[\mathrm{m}^{2} / \mathrm{kWh} / \mathrm{a}\right]$ 
Table 2 Areas classified by CORINE Land Cover (CLC) suitable for the generation of photovoltaic energy

\begin{tabular}{llll}
\hline CLC type & Area $\left[\mathrm{m}^{2}\right]$ & Suitability for PV & Usable area \\
\hline Broad-leaved forest & 118,329 & 0 & 0 \\
Discontinuous urban fabric & 11,793 & 0 & 0 \\
Non-irrigated arable land & 534,318 & 1 & 534,318 \\
Pastures & 8,919 & 1 & 8,919 \\
Total result & 673,359 & & 543,237 \\
\hline
\end{tabular}

post-GIS analysis. This combination may be a new approach and can easily be applied in many regions besides the case study region. Another advantage is that only few basic input data are needed; the unavailability of detailed data is typical for many regions that basically "start from zero".

Another very interesting result, especially for the local experts, was the awareness rising effect of how landconsuming renewable energy production is "in scale" on a 2D cardboard of A0 size, but also how strongly the required amounts of land use among the renewable energy sources differ.

From a planners' perspective, the method really can carry out an interesting regional energy scenario image, aiming for clearly more renewable energy production within a time range of 15 to 20 years. Especially, the cooperation between local experts (e.g., the mayors) and external experts during the workshop resulted in additional (unexpected) solutions that would never have been the output of a mere GIS modelling.

The main advantage of the planning-games-method was that it combined spatial and energy-technical knowledge of various experts in the process of identifying regional renewable energy potentials. By doing so, the method spurs on the discussion about the impacts of setting energy goals and raises awareness for the support of energy transition. Furthermore, the method is capable of providing new insights into the relationship between available and required land for renewable energy production on the scale of the (city) region.

During the practical empirical work, one rather often faces the challenge to deal with insufficient data. For the given goal-to gather information on the path to energy autonomy-it was not of major importance to know everything exactly but rather to identify a way to work with these uncertainties. Providing (rough) estimates and basic data turned out to be sufficient to enable local stakeholders to work on a vision, even a strategy, focusing on the most relevant energy sources. Of course, the results need to be prioritized and revised periodically but definitely can be used to develop an initial (rough) strategy.

The second GIS analysis for adapting the results to more realistic levels also supports the estimation of the potentials of renewable energy sources by focusing on certain areas that local stakeholders have already classified as suitable. Therefore, local knowledge-probably also having in mind which areas might be mobilized for the purpose of energy generation-combined with expert knowledge to calculate a better estimation of possible gains proved to be a very successful and accepted method.

\section{Outlook}

As an outlook, we now want to line up not only what parts of the method have been successful, but also what could not be managed so far. The method shown in this case study has been enhanced and used three more times with different audiences in the meantime. Anytime, the audience was surprised and enthusiastic to "play" the scenario on the scale of a regional level.

Anyway, there are many possibilities to improve the approach in the future:

In the logics of sustainable regional development, it is not enough satisfying to set on ONE single factor $\left(\mathrm{m}^{2} /\right.$ $\mathrm{kWh} / \mathrm{a})$, although this is a crucial aspect. A decent evaluation of the land use competition aspects should be carried out as well. For example, heating with biomass from wooden chips as a waste from forest cultivation has no land-use competition at all, but biomass being harvested from maize has a $100 \%$ competition factor.

Our method also does not yet include an in-depth environmental assessment for all the reference examples, what would be helpful for future versions as well. Fortunately, there is a lot of knowledge and literature on the environmental impacts of renewable energies, e.g., Kaltschmitt et al. [28].

Another weakness of our method is that it cannot help at all to solve or even visualize the complex energy system management that is required to tackle the daily and seasonal fluctuations of the overall energy demand. Furthermore, the storage and distribution patterns that are required to secure a fail-safe energy supply have not been considered so far.

Moreover, energy production scenarios should consider the required amounts not only of end use energy, but also those of primary energy to cover the full lifecycle from the "raw" potential to the "plug", including grey energy as well as emission values after the energy site is closed down. A very interesting and quite complete approach is called "sustainable process index" [10].

Nevertheless, the method turned out to be able to activate the local stakeholders rather easily to provide sometimes sophisticated results. In addition, with the "adjusting" role of the experts not only in the preparation of basic data, but also in the post-processing of results, the method can be useful in the future. This is 
Table 3 Areas classified using zoning data suitable for the generation of photovoltaic energy

\begin{tabular}{llll}
\hline Type of zoning & $\begin{array}{l}\text { Area } \\
{\left[\mathrm{m}^{2}\right]}\end{array}$ & $\begin{array}{l}\text { Suitability for } \\
\text { PV }\end{array}$ & $\begin{array}{l}\text { Usable } \\
\text { area }\end{array}$ \\
\hline Cultivated forest & 101,399 & 0 & 0 \\
Area to be kept clear & 12,607 & 1 & 12,607 \\
Agricultural area & 478,499 & 1 & 478,499 \\
Water body & 25,389 & 0 & 0 \\
Road & 6,107 & 0 & 0 \\
Residential area & 19,049 & 0 & 0 \\
Reserved residential area & 26,989 & 0 & 0 \\
Area for special use-garden & 3,290 & 0 & 0 \\
center & & & 491,105 \\
Total result & 673,329 & & \\
\hline
\end{tabular}

especially true for some of the issues that have not been addressed so far can be improved, such as the competition between renewable energy sources, as well as availability of sufficient data.

\section{Endnote}

During the research Project ERP_hoch3, the authors also considered complex governance tasks:

- What are the minimum sizes of renewable energy sites to become of "regional" importance?

- What is the organizational setup of a regional land management, able to negotiate between energy demand and energy production potential?

- Which are qualitative and quantitative criteria to facilitate the "best" renewable energy site locations?

Table 4 Possible amount of energy production within patch no. 2 per energy source (in kWh per year)

\begin{tabular}{|c|c|c|c|}
\hline Patch no. 2 & $\begin{array}{l}\text { Total area } \\
{\left[\mathrm{m}^{2}\right]}\end{array}$ & 673.329 & \\
\hline & Usable area i & $\mathrm{m}^{2}$ & \\
\hline Zoning type & $\begin{array}{l}\text { Geothermal } \\
\text { (GT) }\end{array}$ & $\begin{array}{l}\text { Photovoltaics } \\
\text { (PV) }\end{array}$ & $\begin{array}{l}\text { Solar- } \\
\text { thermal (ST) }\end{array}$ \\
\hline Cultivated forest & 101,399 & - & - \\
\hline Area to be kept clear & 12,607 & - & - \\
\hline Agricultural area & 478,499 & 478,499 & 478,499 \\
\hline Water body & - & - & - \\
\hline Road & - & - & - \\
\hline Residential area & 19,049 & - & - \\
\hline Reserved residential area & 26,989 & 26,989 & 26,989 \\
\hline $\begin{array}{l}\text { Area for special } \\
\text { use-garden center }\end{array}$ & - & - & - \\
\hline Total & 638,542 & 505,488 & 505,488 \\
\hline $\begin{array}{l}\text { Energy output in kWh per } \\
\text { year }\end{array}$ & $18,243,152$ & $27,801,829$ & $70,768,291$ \\
\hline
\end{tabular}

Those questions were explored with governance analysis methods (mainly guided interviews); the results (actor mappings, regional governance recommendations, list of drivers and barriers of co-operation) are not covered within this paper. They can be found in the long version of the report; see project website.

\section{Endnotes}

${ }^{1}$ This situation is different in Switzerland, where integrated energy and spatial planning has still been highly institutionalized during the past several years, which clearly facilitates the cooperation between planning authorities on the municipality, federal ("Kanton") and national scale. In the Netherlands and in Germany, the regional planning authorities are also much better equipped with financial and human resources as in Austrian districts and regions.

${ }^{2} \mathrm{KEM}$ is an Austrian aid programme to support energy change developments [29].

${ }^{3}$ Vorarlberg, the location of the test area in the study, is a federal state in the very west of Austria, adjacent to Switzerland, Liechtenstein, and Germany

\section{Acknowledgements}

The authors would like to thank all the participants of the scenario workshop for the inspiring contributions in the scenario workshop.

The authors acknowledge the TU Wien University Library for the financial support through its Open Access Funding Program.

\section{Notes on the tables and figures}

Table 1, sources: own site research/measurements except the average biomass and low geothermal harvest values [30]. The samples do not display any energy site records that can combine more than one renewable carrier (e.g., photovoltaic electricity AND geothermal heat production, covering the same area).

All other tables and figures, sources: [31]

\section{Funding}

The project ERP_hoch3 (http://info.tuwien.ac.at/erphoch3/) received funds by the Austrian Ministry for Transport, Innovation and Technology; see http:// www.energiesystemederzukunft.at.

\section{Availability of data and materials}

All data sources presented in this paper can be found in the references and viewed in the full final project report; see http://info.tuwien.ac.at/erphoch3/ index.php/erpmodule.html.

\section{Authors' contributions}

$\mathrm{HD}$ and PN designed and compiled the energy site catalogue together. PN mainly developed the cardboard game workshop setup. KW prepared the energy consumption scenarios as well as the post-GIS analysis. All the authors contributed to the conclusions, the abstract, and the outlook of the case study and read and approved the final manuscript.

\section{Authors' information}

Hartmut Dumke, Pia Nabielek, and Kurt Weninger research and teach at the Vienna University of Technology, Department of Spatial Planning.

Ethics approval and consent to participate Not applicable

Consent for publication

The authors consent to publication. 


\section{Competing interests}

The authors declare that they have no competing interests.

\section{Publisher's Note}

Springer Nature remains neutral with regard to jurisdictional claims in published maps and institutional affiliations.

Received: 28 April 2017 Accepted: 19 December 2017

\section{Published online: 22 January 2018}

\section{References}

1. UNFCC, U.N. (1998) Kyoto protocol to the United Nations framework convention on climate change. https:/unfccc.int/resource/docs/convkp/ kpeng.pdf. Accessed 1 Jun 2017

2. BMWFJ and BMLFUW (2010) Energiestrategie Österreich (2020). http://www. bmwfw.gv.at/Ministerium/Staatspreise/Documents/energiestrategie_ oesterreich.pdf. Accessed 23 Aug 2016

3. European Commission (2014) Mitteilung der Komission an das europäische Parlament, den Rat, den europäischen Wirtschafts-und Sozialausschuss und den Ausschuss der Regionen: Ein Rahmen für die Klima- und Energiepolitik im Zeitraum 2020-2030. http://eur-lex.europa.eu/legal-content/DE/TXT/PDF/ ?uri=CELEX:52014DC0015\&from=de. Accessed 2 May 2017

4. Berchtold-Domig, M., Geitner, C., Hastik, R., Meusburger, P. and Steurer, P. (2015) Musterhektar. http://www.recharge-green.eu/wp-content/uploads/ 2012/12/15-03-11_recharge-green_Musterhektare-booklet150.pdf Accessed $1 \mathrm{Jul} 2017$

5. Kaltschmitt M, Streicher W, Wiese A (2013) Erneuerbare Energien: Systemtechnik, Wirtschaftlichkeit, Umweltaspekte, 5. Aufl., erw. und korr. Nachdruck. Springer, Berlin

6. Quaschning V (2015) Regenerative Energiesysteme: TechnologieBerechnung-Simulation, 9th edn. Hanser, München

7. Hastik R, Walzer C, Haida C, Garegnani G, Pezzutto S, Abegg B, Geitner C (2016) Using the "footprint" approach to examine the potentials and impacts of renewable energy sources in the European Alps. In: Mountain Research and Development, Vol. 36 No. 2, pp 130-140

8. Resch G, Held A, Faber T, Panzer C, Toro F, Haas R (2008) Potentials and prospects for renewable energies at global scale. In: Energy policy, Vol. 36 No. 11, pp 4048-4056

9. Stöglehner, G., Erker, S. and Neugebauer, G. (2013) Tools für die Energieraumplanung. Ein Handbuch für deren Auswahl und Anwendung im Planungsprozess. http://www.oerok.gv.at/fileadmin/Bilder/2.Reiter-Raum_u._ Region/1.OEREK/OEREK_2011/\%C3\%96REK_PS_Publikationen/Tools_ Energieraumplanung_BMLFUW.pdf. Accessed 17 Apr 2015

10. Gwehenberger G, Narodoslawsky M (2008) Sustainable processes-the challenge of the 21 st century for chemical engineering. In: Process safety and environmental protection, Vol. 86 No. 5, pp 321-327

11. Späth $P$, Rohracher $H$ (2010) Energy regions. The transformative power of regional discourses on socio-technical futures. In: Research Policy, Vol 39 No 4, pp 449-458

12. Grêt-Regamey A, Wissen U (2009) Advanced analysis of spatial multifunctionality to determine regional potentials for renewable energies. In: Schrenk M, Popovich W, Elisei P (eds) Proceedings REAL CORP 2009

13. Hallouin, T., Bruen, M., Kelly-Quinn, M. and Feeley, H.B. (2016) Multi-criteria decision analysis and ecosystems services: knowledge gaps and challenges for policy and decision-making. https://www.researchgate.net/publication/ 305379225_Multi-Criteria_Decision_Analysis_and_Ecosystems_Services_ knowledge_gaps_and_challenges_for_policy_and_decision-making. Accessed 11 Nov 2016

14. Vollmer D, Pribadi DO, Remondi F, Rustiadi E, Grêt-Regamey A (2016) Prioritizing ecosystem services in rapidly urbanizing river basins. A spatial multi-criteria analytic approach. In: Sustainable cities and society, vol 20, pp 237-252

15. Blaschke T, Biberacher M, Gadocha S, Schardinger I (2013) Energy landscapes. Meeting energy demands and human aspirations. In: Biomass \& Bioenergy, vol 55, pp 3-16

16. Stöglehner, G., Neugebauer, G. and Erker, S. (2016) Integrated spatial and energy planning: supporting climate protection and the energy turn with means of spatial planning. Accessed 10 Aug 2016. https://doi.org/10.1007/ 978-3-319-31870-7

17. Narodoslawsky, M. (2009) RegiOpt. http://regiopt.tugraz.at/index.php/de/. Accessed 24 Aug 2016
18. Moroni S, Antoniucci V, Bisello A (2016) Energy sprawl, land taking and distributed generation. Towards a multi-layered density. In: Energy Policy, vol 98, pp 266-273

19. Bronin, S.C. (2012) Building-related renewable energy and the case of 360 state street. https://papers.ssrn.com/sol3/papers.cfm?abstract_id=2181635. Accessed $1 \mathrm{Jul} 2017$

20. bmvit (Ed.) (2016) ERP_hoch3, Energieraumplanung für smarte Stadtquartiere und Regionen, Leitfaden 1 (Fokus Stadtquartiere)

21. Statistik Austria (2012) Stromtagebuch Statistik Austria. https://www.statistik. at/web_de/static/projektbericht_strom__und_gastagebuch_2012_071032. pdf. Accessed 24 Oct 2016

22. Land Vorarlberg (2014) Energiekonzept. https://www.energieautonomievorarlberg.at/de/energiekonzept. Accessed 1 May 2016

23. Amt der Vorarlberger Landesregierung (2014) Vorarlbergs Weg zur Energieautonomie. https://www.energieautonomie-vorarlberg.at/zooluwebsite/media/document/1264/Vorarlbergs+Weg+zur+Energieautonomie. Accessed 1 May 2016

24. Albrechts L (2010a) How to enhance creativity, diversity and sustainability in spatial planning: strategic planning revisited. In: Cerreta M, Concilio G, Monno V (eds) Making strategies in spatial planning: knowledge and values. Urban and landscape perspectives, Springer, Dordrecht, New York, pp 3-25

25. Albrechts $L$ (2010b) More of the same is not enough! How could strategic spatial planning be instrumental in dealing with the challenges ahead? In: Environment and planning B: planning and design, Vol. 37 no. 6, pp 1115-1127

26. Shipley R (2002) Visioning in planning. Is the practice based on sound theory? In: Environment and planning A, Vol. 34 No. 1, pp 7-22

27. Sijmons D, Hugtenburg J, van Hoorn A, Feddes F (2014) Landscape and energy. Designing transition. NAl, Rotterdam

28. Kaltschmitt M, Streicher W, Wiese A (2006) Erneuerbare Energien: Systemtechnik. Wirtschaftlichkeit, Umweltaspekte, Springer, Berlin, Heidelberg, New York

29. Klima- und Energiefonds Österreich (2017) Klima- und Energiemodellregionen. https://www.klimaundenergiemodellregionen.at. Accessed 1 Mar 2017

30. Stanzer, G. et al (2010) RegioEnergy. http://regioenergy.oir.at/realisierbares_ potenzial_biomasse_agrar. Accessed 25 Sep 2013

31. Dumke H, Nabielek P, Weninger K (2016) Work package 3. In: bmvit (ed) ERP_hoch3: Energieraumplanung für smarte Stadtquartiere und Regionen, Leitfaden 1 (Fokus Stadtquartiere)

\section{Submit your manuscript to a SpringerOpen ${ }^{\circ}$ journal and benefit from:}

- Convenient online submission

- Rigorous peer review

- Open access: articles freely available online

- High visibility within the field

- Retaining the copyright to your article

Submit your next manuscript at $>$ springeropen.com 